\title{
Super Secondary Structure Consisting of a Polyproline II Helix and a $\beta$-Turn in Leucine Rich Repeats in Bacterial Type III Secretion System Effectors
}

\author{
Dashdavaa Batkhishig ${ }^{1,2} \cdot$ Khurelbaatar Bilguun $^{1,3} \cdot$ Purevjav Enkhbayar $^{1} \cdot$ Hiroki Miyashita $^{4,5}$. \\ Robert H. Kretsinger ${ }^{6} \cdot$ Norio Matsushima ${ }^{1,5,7}$
}

Published online: 12 April 2018

(c) The Author(s) 2018

\begin{abstract}
Leucine rich repeats (LRRs) are present in over 100,000 proteins from viruses to eukaryotes. The LRRs are 20-30 residues long and occur in tandem. LRRs form parallel stacks of short $\beta$-strands and then assume a super helical arrangement called a solenoid structure. Individual LRRs are separated into highly conserved segment (HCS) with the consensus of LxxLxLxxNxL and variable segment (VS). Eight classes have been recognized. Bacterial LRRs are short and characterized by two prolines in the VS; the consensus is xxLPxLPxx with Nine residues (N-subtype) and xxLPxxLPxx with Ten residues (T-subtype). Bacterial LRRs are contained in type III secretion system effectors such as YopM, IpaH3/9.8, SspH1/2, and SlrP from bacteria. Some LRRs in decorin, fribromodulin, TLR8/9, and FLRT2/3 from vertebrate also contain the motifs. In order to understand structural features of bacterial LRRs, we performed both secondary structures assignments using four programs-DSSP-PPII, PROSS, SEGNO, and XTLSSTR - and HELFIT analyses (calculating helix axis, pitch, radius, residues per turn, and handedness), based on the atomic coordinates of their crystal structures. The N-subtype VS adopts a left handed polyproline II helix (PPII) with four, five or six residues and a type I $\beta$-turn at the $C$-terminal side. Thus, the $\mathrm{N}$-subtype is characterized by a super secondary structure consisting of a PPII and a $\beta$-turn. In contrast, the T-subtype VS prefers two separate PPIIs with two or three and two residues. The HELFIT analysis indicates that the type I $\beta$-turn is a right handed helix. The HELFIT analysis determines three unit vectors of the helix axes of PPII (P), $\beta$-turn (B), and LRR domain (A). Three structural parameters using these three helix axes are suggested to characterize the super secondary structure and the LRR domain.
\end{abstract}

Keywords Bacterial leucine rich repeat family $\cdot$ Polyproline II helix $\cdot$ Type I $\beta$-turn $\cdot$ Super secondary structure $\cdot$ Helical parameters $\cdot$ Helix axis $\cdot$ Vector analysis

Electronic supplementary material The online version of this article (https://doi.org/10.1007/s10930-018-9767-9) contains supplementary material, which is available to authorized users.

Purevjav Enkhbayar

enkhbayar.p@seas.num.edu.mn

$\triangle$ Norio Matsushima

norio_irreko@outlook.jp

1 Laboratory of Bioinformatics and Systems Biology, Department of Information and Computer Science, School of Engineering and Applied Sciences, National University of Mongolia, Ulaanbaatar 14201, Mongolia

2 Department of Physics, School of Mathematics and Natural Sciences, Mongolian National University of Education, Ulaanbaatar 210648, Mongolia

\author{
Abbreviations \\ LRR Leucine rich repeat \\ PPII Polyproline II helix \\ HCS Highly conserved segment
}

3 Institute of Physics and Technology, Mongolian Academy of Sciences, Enkhtaivan avenue 54B, Ulaanbaatar 210651, Mongolia

4 Hokubu Rinsho Co., Ltd, Sapporo 060-0061, Japan

Institute of Tandem Repeats, Sapporo 004-0882, Japan

6 Department of Biology, University of Virginia, Charlottesville 22904, USA

7 Sapporo Medical University, Sapporo 060-8556, Japan 


$\begin{array}{ll}\text { VS } & \text { Variable segment } \\ \mathrm{C}_{\alpha} & \alpha \text {-Carbon } \\ \mathrm{CC} & \text { Cysteine containing } \\ P & \text { Helix pitch } \\ R & \text { Helix radius } \\ N & \text { Number of repeat unit/residue per turn in helix } \\ \delta z & \text { Rise per repeat unit/residue in helix } \\ \Delta \Phi & \text { Rotation angle per repeat unit/residue in helix } \\ n & \text { Repeat number of leucine rich repeat } \\ \text { PDB } & \text { Protein data bank } \\ \text { RMSD } & \text { Root mean square deviation } \\ \text { TLR } & \text { Toll like receptor } \\ \text { SLRP } & \text { Small leucine rich repeat proteoglycan protein } \\ \text { FLRT } & \text { Fibronectin leucine rich repeat transmembrane } \\ & \text { protein } \\ \text { CTD } & C \text {-terminal repeat domain of the large subunit of } \\ & \text { RNA polymerase II } \\ \text { POL II } & \text { RNA polymerase II }\end{array}$

\section{Introduction}

Leucine rich repeats (LRRs) are unusually rich in leucine [1-6]. The LRRs are composed of 20-30 residues stretches and repeat in tandem. The published repeat numbers range from 2 to 97. LRRs have been reported in over 100,000 proteins from viruses to eukaryotes.

LRR units are divided into a highly conserved segment (HCS) and a variable segment (VS) [1]. Eight classes of LRRs have been recognized [3]. Matsushima and Kretsinger recently proposed twenty-three types of LRRs [1]. Their grouping is based mainly on the difference of the VS parts. The eight classes are RI-like, cysteine containing (CC), SDS22-like, IRREKO, bacterial, plant specific, typical, and TpLRR.

The HCS part consists of an 11 or 12 residue stretch, $\operatorname{Lx} \underline{\operatorname{Lx}} \operatorname{Lxx}(\mathrm{N} / \mathrm{C})(\mathrm{x} /-) \mathrm{L}$, in which " $\mathrm{L}$ " is Leu, Ile, Val, or Phe, "N" is Asn, Thr, Ser, or Cys, "C" is Cys, Ser or Asn, " $\mathrm{x}$ " is any amino acid, and "-" is a deletion. Three residues at positions $3-5$ in the underlined residues form a short $\beta$-strand [4, $6]$. These $\beta$-strands stack parallel; they have the pattern of $\mathrm{H}$-bonding $(\mathrm{N}-\mathrm{H} \rightarrow \mathrm{O}=\mathrm{C})$, and then these tandem repeats of LRRs assume their super helical arrangements. The LRRs fold into a horse shoe, a right handed or left handed helix, or a prism shape [7]. Conserved hydrophobic residues such as leucine, valine, isoleucine, or phenylalanine in the consensus sequences of LRRs contribute to the hydrophobic cores. Capping structures that shield the hydrophobic core of the first LRR unit at the $N$-terminus and/or the last unit at the $C$-terminus are observed in most of the known LRR structures $[1,5]$.

Characteristic of each LRR class, the VS parts adopt a variety of secondary structures including the $\alpha$-helix, $3_{10}$-helix, and an extended conformation or a tandem arrangement of $\beta$-turns $[1,6]$. Their secondary structures on the convex side are connected to the strands forming the $\beta$-sheet on its concave side by two loops [5]. One of the loops is an "ascending loop" which links the $C$-terminus of the HCS to the $N$-terminus of the VS. The other is a "descending loop" which links the $C$-terminus of the VS to the $N$-terminus of the HCS of the following unit. Each LRR domain contains a concave surface, a convex surface, an ascending surface, and a descending surface on the opposite side. LRR domains are involved in direct interaction with proteins (including hormones) or ligands (including nucleic acid, lipid, lipo-polysaccharide, and plant steroid hormones) [1]. LRR domains can engage structurally various proteins or ligands using different surfaces of the LRR domains [1, 5].

LRR proteins participate in the plant immune response and in the mammalian innate immune response [1-6]. They are also involved in a broad range of functions including apoptosis, autophagy, ubiquitin related processes, nuclear mRNA transport, and neuronal development [1, 8]. Plant LRR proteins, many of which involve kinases and other receptor like proteins, act as signal amplifiers in tissue damage, in symbiotic relationships, and in developmental processes $[1,9]$.

Furthermore, LRR proteins are contained in the type III secretion system of many gram-negative bacterial pathogens. The LRR proteins called effectors are delivered into the cytosol of animal or plant cells [10]. Consequently, these effectors enable the bacteria to avoid the immune response of the infected organism by modulating cell functions of the host. The effector proteins include YopM from the bubonic plague bacterium, Yersinia pestis, and $\mathrm{SspH} 1, \mathrm{SspH}$, and SlrP from Salmonella enterica, and IpaH3 and IpaH9.8 from Shigella flexneri. These effectors are bacterial LRR proteins [1]. The LRR domain of SspH1 directly interacts with PKN1 [11].

Bacterial LRRs are characterized by two Leu Pro sequences in the VS; the consensus is xxLPxLPxx with Nine residues (N-subtype) and xxLPxxLPxx with Ten residues (T-subtype) where " $\mathrm{L}$ " is Leu, Val, or Ile and " $\mathrm{x}$ " is predominantly occupied by small residues such as Thr, Ser, or Gly. T-subtype is seen in Salmonella SlrP. Moreover, LRRs in the subfamily of toll-like receptors (TLR7, TLR8, and TLR9), the small leucine rich repeat proteoglycan (SLRP) family including fibromodulin, decorin and biglycan, and the fibronectin leucine rich repeat transmembrane family (FLRT) contains N- or T-subtype [1]. The LRRs consist of tandem repeats of a super motif of $S T T$ or $S T$ in which " $S$ " is Bacterial and " $T$ " is Typical [12-14]. We called this the STT class [1].

PPIIs are known to be observed frequently in proline rich regions [15-19]. The PPIIs are characterized by the 
backbone dihedral angles $(\Phi, \Psi)$ of $\left(-75^{\circ}, 145^{\circ}\right)$ [20-29]. The PPIIs have helical parameters: 2.9 residues per turn, a pitch value of $8.7 \AA$ A per turn, and a helix radius of $1.33 \AA$. The assignment of PPII is not done in the widely used programs such as DSSP [28] and STRIDE [29]. Consequently, PPIIs in newly solved protein structures are not registered in protein data bank (PDB) [30]. Now there are some tools for assigning PPII number-DSSP-PPII [31], PROSS [32], SEGNO [33], XTLSSTR [34], and ASSP [35].

Super secondary structures with several adjacent elements of a secondary structure are also observed in protein structures [36, 37]. Examples include $\beta$-hairpins, $\alpha$-helix hairpins, and $\beta-\alpha-\beta$ motifs. Adzhubei and Sternburg [38] identified super secondary structures consisting of PPII and $\alpha$-helix and of $3_{10}$-helix and PPII. Kumar and Bansal [27] also identified those consisting of $\beta$-strand and PPII, of $\beta$-strand, PPII, and $\alpha$-helix, and of $\beta$-strand, PPII, and $\beta$-strand.

Evdokimov et al. [39] noted that the VS parts in the YopM LRRs adopt 310 -helices. Matsushima et al. [6, 7], Bella et al. [5], and Park et al. [40] proposed that the VS parts in the bacterial LRR adopt left handed polyproline II helices (PPII). A review article by Adzhubei et al. [41] noted PPIIs in LRRs. However, it appears that PPII in LRR structures has not yet been well characterized based on the consensus sequence. Structural data of proteins containing bacterial LRRs have increased. The crystal structures of YopM, SspH1, SspH2, SlrP, IpaH3, and IpaH9.8 have been determined [39, 42-46]. The structures of TLR8, TLR9, fibromodulin, decorin, biglycan, FLRT2, and FLRT3 are also available [47-56].

The purpose of this study is to understand structural features of bacterial LRRs. We performed both the secondary structures analyses using secondary structures prediction programs of DSSP-PPII, PROSS, SEGNO, and XTLSSTR and the HELFIT analyses that calculate helix axis, helix pitch, helix radius, repeat/residue number per turn, based on the atomic coordinates of the crystal structures [57].

This present analysis demonstrates that the N-subtype VS adopts PPII consisting of $4-6$ residues and type I $\beta$-turn at the $C$-terminal side. Thus, the VS part is characterized by super secondary structure consisting of PPII and a $\beta$-turn. In contrast, the T-subtype VS frequently prefers two separate PPIIs consisting of two or three and of two residues. The HELFIT analysis indicates that the type I $\beta$-turn is a right handed helix and consequently determines three unit vectors of the helix axes of PPII (P), $\beta$-turn (B), and LRR domain (A). We propose three structural parameters which are two angles between the two helix axes of PPII and $\beta$-turn, between the two helix axes of PPII and LRR domain, and between the helix axis of LRR domain and the vector product of $\mathbf{P} \times \mathbf{B}$. These three angles are suggested to characterize the super secondary structure and the LRR domain.

\section{Methods}

\subsection{Structure Data}

We collected the structure data of proteins containing bacterial LRRs from the PDB. We performed sequence alignments in LRR proteins from the PDB by LRRpred that recognizes and aligns LRR motifs that predict the repeat number and "phasing" of LRRs with greater reliability [58] and identified bacterial LRR based on the consensus sequence. Bacteria LRR proteins are YopM, SspH1, SspH2, SlrP, IpaH3, IpaH9.8, TLR8, TLR9, fibromodulin, decorin, biglycan, FLRT2, and FLRT3 (Table 1) [39, 42-56]. LRRs in YopM, SspH1, SspH2, SlrP, IpaH3, and IpaH9.8 belong to bacterial LRR class, while TLR8, TLR9, fibromodulin, decorin, biglycan, FLRT2, and FLRT3 belong to the STT class (Table 1). Eighteen PDB files solved at resolution $\leq 3.4 \AA$ were used; the sequence identity of the 18 different chains shows that the maximum is $48 \%$ and the average is $7 \%$ (Supplementary Table S1). The structure data of mouse FLRT2 at resolution 4.0 and $6.0 \AA$ A were not used for analyses.

\subsection{Secondary Structures Analysis}

Secondary structures assignments were made from the atomic coordinates of the LRR structures using four programs-DSSP-PPII [31], PROSS [32], SEGNO [33], and XTLSSTR [34]. The assignment of the DSSP program is based on the identification of precise hydrogen bond patterns corresponding to regular secondary structures [28]. In DSSP-PPII based on DSSP, PPII are assigned solely in the coil region for at least two consecutive residues in coil with $\Phi=-75^{\circ} \pm 29^{\circ}$ and $\Psi=+145^{\circ} \pm 29^{\circ}$. The PROSS program assigns secondary structures, based mainly on $\Phi$ and $\Psi$ dihedral angles. SEGNO utilizes the $\Phi$ and $\Psi$ dihedral angles coupled with other angles. XTLSSTR uses two angles and three distances. DSSP-PPII, PROSS, and XTLSSTR assign $\beta$-turns; while SEGNO does not. The secondary assignments were performed using the PolyprOnline web interface [59]. Types of $\beta$-turn were also identified by the programs of PROMOTIF [60] and STRIDE [61]. Furthermore, the root-mean-square deviation (RMSD) of the VS part between within the N-subtype and within the T-subtype and between these two subtypes using the coordinates of the backbone atoms of each residue were evaluated by the CHIMERA program [62]. 
Table 1 Known structures of proteins containing bacterial LRRs

\begin{tabular}{|c|c|c|c|c|c|c|c|c|}
\hline $\begin{array}{l}\text { Number of } \\
\text { protein }\end{array}$ & LRR class & Protein name & $\begin{array}{l}\text { Repeat num- } \\
\text { ber of } L^{2} R^{a}\end{array}$ & $\begin{array}{l}\text { Number of } \\
\text { N-subtype }\end{array}$ & $\begin{array}{l}\text { Number of } \\
\text { T-subtype }\end{array}$ & PDBID & Chains & Resolution $(\AA)$ \\
\hline \multirow[t]{2}{*}{1} & Bacterial & Y. pestis уорМ & $16(16)$ & 13 & 0 & 1JL5 & A & 2.10 \\
\hline & Bacterial & $Y$. pestis yopM & $16(16)$ & 13 & 0 & $1 \mathrm{G} 9 \mathrm{U}$ & A & 2.35 \\
\hline 2 & Bacterial & Y. entercocolitica yорМ & $21(20)$ & 19 & 0 & 4OW2 & A,B,C,D & 3.20 \\
\hline \multirow[t]{2}{*}{3} & Bacterial & S. enterica $\mathrm{SspH} 1$ & $10(9)$ & 6 & 1 & $4 \mathrm{NKH}$ & A,B,C,D,E,F & 2.75 \\
\hline & Bacterial & S. enterica $\mathrm{SspH} 1$ & $10(9)$ & 6 & 1 & $4 \mathrm{NKG}$ & $\mathrm{A}, \mathrm{C}$ & 2.90 \\
\hline 4 & Bacterial & S. enterica $\mathrm{SspH} 2$ & $13(13)$ & 10 & 1 & $3 \mathrm{G} 06$ & A & 1.90 \\
\hline 5 & Bacterial & S. flexneri ipaH3 & $9(9)$ & 5 & 1 & $3 \mathrm{CVR}$ & A & 2.80 \\
\hline \multirow[t]{2}{*}{6} & Bacterial & S. flexneri ipa9.8 & $8(8)$ & 5 & 1 & $5 \mathrm{~B} 0 \mathrm{~N}$ & $\mathrm{~A}, \mathrm{~B}$ & 1.80 \\
\hline & Bacterial & S. flexneri ipa9.8 & $8(8)$ & 5 & 1 & 5B0T & A & 2.00 \\
\hline 7 & Bacterial & S. enterica SlrP & $12(12)$ & 0 & 10 & 4PUF & $\mathrm{A}, \mathrm{B}$ & 3.30 \\
\hline 8 & STT & Human fibromodulin & $13(12)$ & 2 & 2 & $5 \mathrm{MX} 0$ & $\mathrm{~A}, \mathrm{~B}$ & 2.21 \\
\hline \multirow[t]{3}{*}{9} & STT & Horse TLR9 & $27(27)$ & 1 & 1 & $3 \mathrm{WPC}$ & $\mathrm{A}, \mathrm{B}$ & 1.60 \\
\hline & STT & Horse TLR9 & $27(27)$ & 1 & 1 & $3 \mathrm{WPB}$ & A & 2.40 \\
\hline & STT & Horse TLR9 & $27(27)$ & 1 & 1 & 3WPD & A & 2.75 \\
\hline 10 & STT & Bovine TLR9 & $27(27)$ & 1 & 1 & $3 \mathrm{WPE}$ & A & 2.38 \\
\hline \multirow[t]{4}{*}{11} & STT & Mouse TLR9 & $27(27)$ & 1 & 1 & $3 \mathrm{WPF}$ & A & 1.96 \\
\hline & STT & Mouse TLR9 & $27(27)$ & 1 & 1 & 3WPG & A & 2.25 \\
\hline & STT & Mouse TLR9 & $27(27)$ & 1 & 1 & 3WPI & A & 2.25 \\
\hline & STT & Mouse TLR9 & $27(27)$ & 1 & 1 & $3 \mathrm{WPH}$ & A & 2.35 \\
\hline \multirow[t]{7}{*}{12} & STT & Human TLR8 & $27(27)$ & 0 & 3 & 3WN4 & A & 1.81 \\
\hline & STT & Human TLR8 & $27(27)$ & 0 & 3 & $3 \mathrm{~W} 3 \mathrm{~J}$ & $\mathrm{~A}, \mathrm{~B}$ & 2.00 \\
\hline & STT & Human TLR8 & $27(27)$ & 0 & 3 & $3 \mathrm{~W} 3 \mathrm{~N}$ & $\mathrm{~A}, \mathrm{~B}$ & 2.10 \\
\hline & STT & Human TLR8 & $27(27)$ & 0 & 3 & $3 W 3 G$ & $\mathrm{~A}, \mathrm{~B}$ & 2.30 \\
\hline & STT & Human TLR8 & $27(27)$ & 0 & 3 & $3 \mathrm{~W} 3 \mathrm{~K}$ & $\mathrm{~A}, \mathrm{~B}$ & 2.30 \\
\hline & STT & Human TLR8 & $27(27)$ & 0 & 3 & $3 \mathrm{~W} 3 \mathrm{~L}$ & A,B,C,D & 2.33 \\
\hline & STT & Human TLR8 & $27(27)$ & 0 & 3 & $3 \mathrm{~W} 3 \mathrm{M}$ & A & 2.70 \\
\hline \multirow[t]{3}{*}{13} & STT & Bovine decorin & $12(12)$ & 0 & 3 & $1 \mathrm{XKU}$ & A & 2.15 \\
\hline & STT & Bovine decorin & $12(12)$ & 0 & 3 & $1 \mathrm{XEC}$ & $\mathrm{A}, \mathrm{B}$ & 2.30 \\
\hline & STT & Bovine decorin & $12(12)$ & 0 & 3 & $1 \mathrm{XCD}$ & A & 2.31 \\
\hline 14 & STT & Bovine biglycan & $12(12)$ & 0 & 3 & 2FT3 & $\mathrm{A}, \mathrm{B}, \mathrm{C}, \mathrm{D}, \mathrm{E}, \mathrm{F}$ & 3.40 \\
\hline 15 & STT & Human TLRT2 & $13(13)$ & 0 & 3 & $4 \mathrm{~V} 2 \mathrm{D}$ & A & 2.50 \\
\hline 16 & STT & Mouse TLRT2 & $13(13)$ & 0 & 3 & 5FTT & $\mathrm{B}, \mathrm{F}$ & 3.40 \\
\hline 17 & STT & Human TLRT3 & $13(13)$ & 0 & 3 & $5 \mathrm{CMP}$ & A,B,C,D & 2.60 \\
\hline \multirow[t]{2}{*}{18} & STT & Mouse FLRT3 & $13(13)$ & 0 & 3 & $4 \mathrm{~V} 2 \mathrm{E}$ & $\mathrm{A}, \mathrm{B}$ & 2.50 \\
\hline & STT & Mouse FLRT3 & $12(12)$ & 0 & 3 & 2YEB & $\mathrm{B}, \mathrm{F}$ & 3.19 \\
\hline
\end{tabular}

${ }^{a}$ The number in the parentheses indicates the number of variable segment of LRRs

\subsection{HELFIT Analysis}

We have developed a total least squares program for fitting a helix to data points-HELFIT [57]. A helix consisting of $n$ repeat units may be characterized by helix axis, helix pitch $(P)$, helix radius $(R)$, and number of repeat units/ residue per turn $(N)$. HELFIT computes these parameters in which the helix axis is represented by the unit vector. These parameters also yield the rise per repeat unit/residue $(\Delta z=P / N)$ and the rotation per repeat unit/residue in the helix $\left(\Delta \Phi=360^{\circ} / N\right)$. Moreover, HELFIT gives $r m s d$ : where $d_{\mathrm{i}}$ is the closest distance from the data point to the trace of the helix.

$r m s d=\left[\left(\text { the minimum of } \sum d_{\mathrm{i}}\right) / N\right]^{1 / 2}$

Here $p=r m s d /(n-1)^{1 / 2}$ gives the regularity of helical structures independent of the number of data points or helix length. The criterion for regular PPII helices is $p \leq 0.10 \AA$. This same test is used for $\alpha$-helices, $\omega$-helices, 
and $31_{10}$-helices in proteins $[63,64]$. The HELFIT analysis requires only four data points: the coordinates of $\alpha$-carbon $(\mathrm{C} \alpha)$ of each residue. LRRs form a $\beta$-strand of three residues at positions 3-5 in the HCS part. Thus, in LRRs, the $\mathrm{C}_{\alpha}$ coordinates of the consensus leucine residue at position four in individual LRR repeat units are used. The repeat number of individual LRR domains was defined as the number that participates in the parallel $\beta$-sheet. This definition means that the first LRR is sometimes contained in the capping structures. $\beta$-Turns consist of four amino acid residues (labelled $i, i+1, i+2$, and $i+3$ ). We also estimate the helical parameters of $\beta$-turns using the $C_{\alpha}$ coordinates of each residue.

The HELFIT analysis indicates that the $\beta$-turn is regarded as a right handed helix, as noted later. Consequently, HELFIT determines three unit vectors of the helix axes of LRR domain (A), PPII (P), and type I $\beta$-turn (B). We estimate three structural parameters. One is the angle between the two helix axes of PPII and $\beta$-turn $\left(\Omega_{1}\right)$. The second is the angle between the two helix axes of PPII and LRR domain $\left(\Omega_{2}\right)$. The third is the angle between the helix axis of LRR domain and the vector product of $\mathbf{P} \times \mathbf{B} .\left(\Omega_{3}\right)$. The three angles of $\Omega_{1}, \Omega_{2}$, and $\Omega_{3}$ are represented by the following equations.

$$
\begin{aligned}
& \mathbf{P} \cdot \mathbf{B}=|\mathbf{P}||\mathbf{B}| \cos \Omega_{1} \\
& \mathbf{P} \cdot \mathbf{A}=|\mathbf{P}||\mathbf{A}| \cos \Omega_{2} \\
& (\mathbf{P} \times \mathbf{B}) \cdot \mathbf{A}=|\mathbf{P} \times \mathbf{B}||\mathbf{A}| \cos \Omega_{3}
\end{aligned}
$$

\section{Results}

\subsection{Two Subtypes of Consensus Sequences}

Bacterial LRR is 20 or 21 residues long and is classified into two subtypes. The $\mathrm{N}$-subtype has the VS consensus of xxLPxLPxx with nine residues and the T-subtype has xxLPxxLPxx with ten residues where " $L$ " is Leu, Val, or Ile and " $x$ " is predominantly occupied by small residues such as Thr, Ser, or Gly (Fig. 1). Thus bacterial LRR is characterized by two Leu Pro sequences in the VS parts; although variable VS that lack one of the two conserved prolines is observed. The characteristics are not seen in other LRR classes. For examples, ribonuclease inhibitors and Nod-like receptors contain RI-like LRRs which of the consensus is

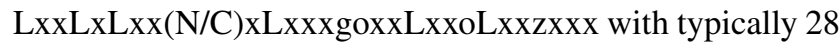
or 29 residues [65].

The $\mathrm{N}$-subtype appears sixty-three times in the known structures (Table 1). The VS consensus is xxLPxLPxx, as expected, in which "x" positions at the $N$ - and $C$-terminal sides are frequently occupied by relatively small residues such as Thr or Ser; while the central "x" position is rich in Glu. Fifty-two of the sixty-three VS are completely consistent with the consensus (Fig. 1a). The remaining VSs are xxLxxLPxx in YopM; the conserved Pro at position four is replaced by Cys or Ser. The T-subtype appears forty-three times (Table 1). The conserved Leu at position three in the VS consensus is frequently occupied by other hydrophobic residues such as Val or Ile (Fig. 1b).
Fig. 1 Consensus sequence of variable segment (VS) of bacterial LRRs in the known structures. a N-subtype; b T-subtype. The graphical sequence diagrams were generated with WebLogo [78], representing sixty-three LRR units for the $\mathrm{N}$-subtype and forty-three for the T-subtype

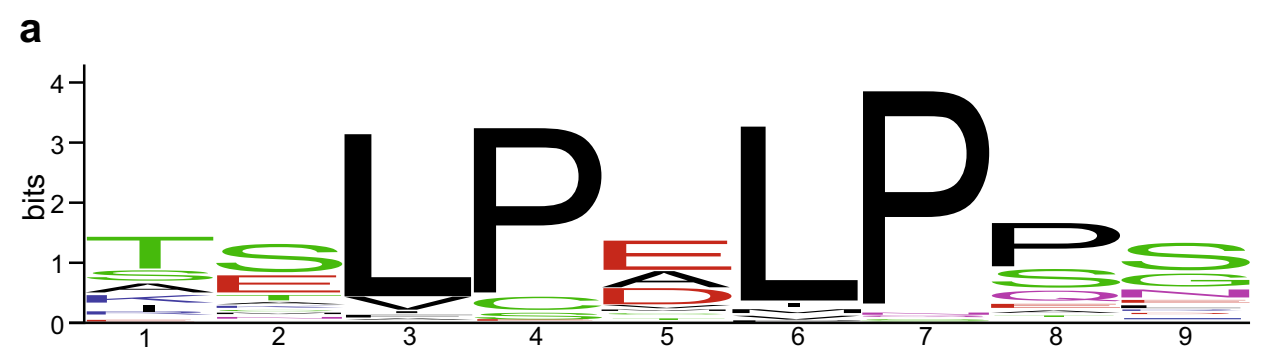

b

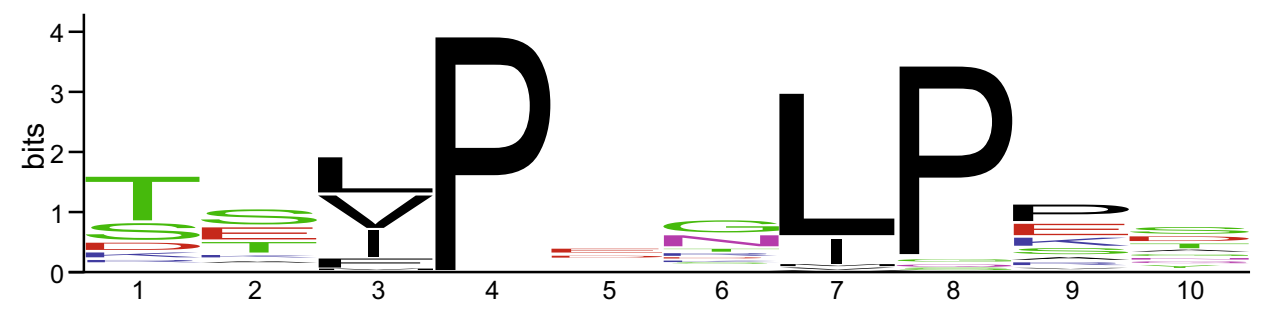




\subsection{Secondary Structures}

The assignment of PPII patterns differs among the four programs. Bacterial LRR proteins form not only monomers but also homo-dimers, -tetramers, and -hexamers in crystals (Table 1). The PPII patterns assigned also differ among their individual molecules. We therefore analyzed all chains of the known structures.

The four programs for secondary structures assignment indicate that the HCS parts adopt short $\beta$-strands in three underlined residues of Lx $\underline{\mathbf{x} L \mathbf{x}} \mathrm{LxxNxL}$. In addition, the assignment indicates that the VS parts are rich in PPII conformations. However, the secondary structures show a difference between the two subtypes.

At least one of the four programs of secondary structures assignment indicates that the N-subtype VS adopts PPIIs consisting of four, five or six residues (Fig. 2a; Supplementary Table S2). Four, five or six residue PPIIs are observed in the underlined residues of xxLPxLPxx, xxLPxLPxx, and xxLPxLPxx, respectively. For example, all four

a

N-subtype

\begin{tabular}{|c|c|c|c|c|c|}
\hline $\mathrm{VS} \mathrm{s}$ & $\begin{array}{c}\mathrm{SspH} 2 \\
L R R 2 \\
\text { SLPALPPE }\end{array}$ & $\begin{array}{c}\mathrm{SspH} 2 \\
\text { LRR3 } \\
\text { SLPVLPPG }\end{array}$ & $\begin{array}{c}\mathrm{SspH} 2 \\
\text { LRR4 } \\
\text { HLPALPSG }\end{array}$ & $\begin{array}{c}\mathrm{SspH} 2 \\
\text { LRR5 } \\
\text { TSLPVLPPG }\end{array}$ & $\begin{array}{c}\mathrm{SspH} 2 \\
\text { LRR6 } \\
\text { ASLPALPSE }\end{array}$ \\
\hline III & $-\mathrm{PP}$ & $----\mathrm{PPTT}$ & $---\mathrm{PPPTT}$ & $\mathrm{PPTT}$ & $\mathrm{S}--\mathrm{PPPPTT}$ \\
\hline $\mathrm{RC}$ & PTT & $---\mathrm{P}-\mathrm{PPTT}$ & -EЕEPPPTT & ---PPPPTT & $---\mathrm{PPPPTT}$ \\
\hline SEGNO & $--\mathrm{PPPPp}--$ & $--\mathrm{PPPPp}--$ & $--\mathrm{PPPPp}--$ & $--\mathrm{PPPPp}--$ & $--\mathrm{PPPPp}--$ \\
\hline XTLSSTR & EEePPPPTT & EEePPPPTT & EEePPPPTT & EEePPPPTT & EEePPPPTT \\
\hline
\end{tabular}

\begin{tabular}{|c|c|c|c|c|c|}
\hline VS sequence & $\begin{array}{c}\mathrm{SspH} 2 \\
L R R 7 \\
\text { TSLPMLPSG }\end{array}$ & $\begin{array}{c}\mathrm{SspH} 2 \\
\text { LRR } 8 \\
\text { ASLPTLPSE }\end{array}$ & $\begin{array}{c}\mathrm{SspH} 2 \\
\text { LRR9 } \\
\text { TSLPALPSG }\end{array}$ & $\begin{array}{c}\mathrm{SspH} 2 \\
\text { LRR10 } \\
\text { TSLPVLPSE }\end{array}$ & $\begin{array}{c}\mathrm{SspH} 2 \\
\text { LRR11 } \\
\text { TSLPMLPSG }\end{array}$ \\
\hline DSSP-PPII & $\mathrm{S}--\mathrm{PPPPTT}$ & $\mathrm{S}---\mathrm{PPPTT}$ & $\mathrm{SS}-\mathrm{PPPPTT}$ & $\mathrm{S}---\mathrm{PPPTT}$ & $\mathrm{S}---\mathrm{PPPTT}$ \\
\hline PROSS & ---PPPPTT & $----\mathrm{PPPTT}$ & ---PРPРTT & $----\mathrm{PPPTT}$ & $----\mathrm{PPPTT}$ \\
\hline SEGNO & $--\mathrm{PPPPp}--$ & $--\mathrm{PPPPp}--$ & $-\mathrm{pPPPPp}--$ & $--\mathrm{PPPPp}--$ & $--\mathrm{PPPPp}--$ \\
\hline XTLSSTR & EEePPPPTT & EEePPPPTT & EEePPPPTT & $---\mathrm{PPPPTT}$ & EEePPPPTT \\
\hline
\end{tabular}

b

T-s ubtype

\begin{tabular}{lccccc}
\hline Protein & SspH2 & Bovine TLR9 & Human TLR8 & Human TLR8 & Human TLR8 \\
& LRR1 & LRR7 & LRR1 & LRR4 & LRR7
\end{tabular}

VS sequence TTLPDCLPAH TTVPRSLPPS QEVPQTVGKY PQIPSGLPES SHVPPKLPSS

\begin{tabular}{|c|c|}
\hline II & $---\mathrm{S}---\mathrm{TT}$ \\
\hline ROS & PTT --PPTTPPTT - \\
\hline EGNO & $-----\mathrm{pPp}---$ pPPp----- ---------- -- PPp ----- -pPPp----- \\
\hline TLSSTR & --Pp-РpTT EePPPPPPTT \\
\hline
\end{tabular}

Fig. 2 Secondary structure assignment of the variable segment (VS) of representative bacterial LRRs by the four programs (DSSP-PPII, PROSS, SEGNO, and XLTSSTR). a N-subtype, SspH2 (PDB ID: 3G06_A). b T-subtype, SspH2 (LRR1) (PDB ID: 3G06_A), Bovine
TLR9 (LRR7) (PDB ID:3WPC_A) and Human TLR8 (LRR1, LRR4, and LRR7) (PDB ID: 3WN4_A). A one letter code is used to represent a specific conformation; $\mathrm{P}$ and $\mathrm{p}, \mathrm{PPII} ; \mathrm{E}$ and e, $\beta$-strand; T, $\beta$-turn; N, non-hydrogen-bonded $\beta$-turn; $\mathrm{H}, \alpha$-helix; and $\mathrm{S}$, bend 
program assign PPII in underlined residues of KKLPDLPLS (LRR7) in Y. pestis YopM $(n=12)$ [3G06_A] (Fig. 2a). The variable VS of xxLxxxLPxx frequently adopt four or five PPIIs. The HELFIT analysis demonstrated that all of the PPIIs assigned are definitely left handed polyproline helices, as noted later.

In addition, the programs identified $\beta$-turns at the $C$-terminal side in the VS parts. The sequences in the underlined residues of xxLPxLPxxLxxLxLxxNxL adopt $\beta$-turns; the second conserved Pro corresponds to the residue, $i$, of $\beta$-turns. The types are distinguished by the $\Phi, \Psi$, angles of residues $i+1$ and $i+2$. The average $\mathrm{C} \alpha(i)-\mathrm{C} \alpha(i+3)$ is $5.48(0.22 \AA)$; the numbers in parenthesis are standard deviations; they are reasonable [66]. The $\Phi, \Psi$ angles of residues $i+1$ and $i+2$ of the $\beta$-turns have the average angles of $\Phi_{i+1}=-60.7\left(8.8^{\circ}\right), \Psi_{i+1}=-22.6\left(8.4^{\circ}\right), \Phi_{i+2}=-94.0$ $\left(13.8^{\circ}\right), \Psi_{i+2}=3.4\left(14.0^{\circ}\right)$; the numbers in parentheses are standard deviations. These values are close to $-60^{\circ},-30^{\circ}$ and $-90^{\circ}, 0^{\circ}$ which define the type I $\beta$-turns. The $\beta$-turns assignments by PROMOTIF [60] and STRIDE [61] give the same results and indicate that most of the $\beta$-turns are type I (Table 2). Types IV and VIII rarely appear. Also very rarely $\beta$-turns are not assigned.

In the T-subtype VS PPIIs assigned may be divided into three patterns. Many VSs adopt two separate PPIIs with two or three and two residues, which are observed in the

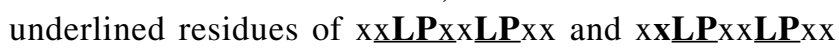
(Fig. 2b; Supplementary Table S2). The second is one PPIIs with three or four residues in the underlined residues of $x x \underline{L} x x L P x x, x x L P x \underline{x} \mathbf{L P x}$ or xxLPxxLPxx. The third pattern is six residue PPII in the underlined residues of xxLPxxLPxx, which are seen in decorin, TLR9, and TLR8 by the XLTSSTR program. Moreover, the $C$-terminal two residues of the T-subtype VS are assigned to adopt mostly type I $\beta$-turn as does that of the $\mathrm{N}$-subtype VS.

The average RMSD of the VS parts of the $\mathrm{N}$-subtypes and of the T-subtypes is $0.589(0.315 \AA)$ and $0.993(0.337 \AA)$, respectively; all Bacterial VSs show the RMSD of 1.087 (0.549 ̊).

In conclusion the N-subtype VS is characterized by a super secondary structure consisting of PPII with four, five, or six residues and a type I $\beta$-turn (Fig. 3), while the T-subtype VS strongly prefers one or two separate PPIIs and adopts a type I $\beta$-turn at the $\mathrm{C}$-terminal side as does the

Table 2 Types of $\beta$-turns at the $C$-terminal side in the bacterial LRRs

\begin{tabular}{lccc}
\hline & DSSP-II & PROSS & XLTSSTR \\
\hline Type I & 66 & 87 & 137 \\
Type IV & 5 & 5 & 5 \\
Type VIII & 1 & 0 & 1 \\
Total & 72 & 92 & 143 \\
\hline
\end{tabular}

$\mathrm{N}$-subtype VS. It appears that the structure of the T-subtype is more variable.

\subsection{Helical Parameters of PPIIs, Type I $\beta$-turns, and LRR Domains}

The number of assigned PPII of which the helix length is longer than three residues increase in order of DSSPPPII $<$ PROSS $<$ XLTSSTR $<$ SEGNO (Table 3). SEGNO assigns longer PPIIs. Four residue PPIIs are regular and thus are a near ideal form (Table 2). All of five and six residue PPIIs are irregular. The helix regularity decreases with increasing helix length. The deviation of helix parameters from ideal values increases with increasing helix length. The helix irregularities in the five and six residue PPIIs are mostly due to larger deviations of the $\Phi, \Psi$ angles from ideal: $-75^{\circ}, 145^{\circ}$ in the first and/or second residues of N-terminal side in the sequence of xLPxLP. The sequence of VP(A/R)LP in TLR9 (LRR4), which corresponds to the underlined residues of xxLPxLPxx, adopt five residue PPIIs with large helix irregularity; $p=0.41-0.47 \AA$. In this case, the irregularity comes from large deviation of the $\Phi, \Psi$ angles of the conserved Leu at the $C$-terminal side. Taking account of the helical parameters, the five residue PPIIs are regarded as a highly deformed form. Consequently, the HELFIT analysis demonstrated that all four, five, and six residue PPIIs assigned by the secondary structures analyses are regular or irregular left handed polyproline helices.

In the T-subtype only the XLTSSTR program identifies long PPIIs with six residues in $L R R 7$ of horse/bovine TLR9, LRR 4 of human TLR8, and LRR4 of decorin, as noted. The $p$ values are very large; $p=0.38-0.50 \AA$ (Table 3 ). The high irregularity comes from the $\Phi, \Psi$ angle of any residue at position six in the T-subtype VS consensus of xxLPxxLPxx; the $\Phi, \Psi$ angles are in regions of a left handed $\alpha$-helix. In addition, the helical parameters deviate highly from those of ideal form (Table 3). The six residue PPIIs assigned are not recognized as a PPII. Alternatively, the SEGNO program identifies regular, four residue PPIIs in the underlined

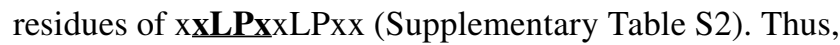
the six residue PPIIs may be divided into two separate PPIIs with three and two residues. This supports the conclusion by the secondary structure assignment that the T-subtype VS contains two separate PPIIs.

The average helix parameters of the type I $\beta$-turns are; $P=6.11 \rightarrow 6.14 \AA, N=3.65 \rightarrow 3.68$ residues/turn, $R=2.26$ $\rightarrow 2.28 \AA$, and $\Delta z=1.68 \rightarrow 1.69 \AA$ (Table 4). It appears that the helical parameters are close to those of $\alpha$-helix as it has $P=5.4 \AA$, $N=3.6$ residues/turn, $R=2.4 \AA$, and $\Delta z=1.5 \AA$. The average $p$ value is $0.02 \rightarrow 0.03 \AA$. The HELFIT analysis 
a

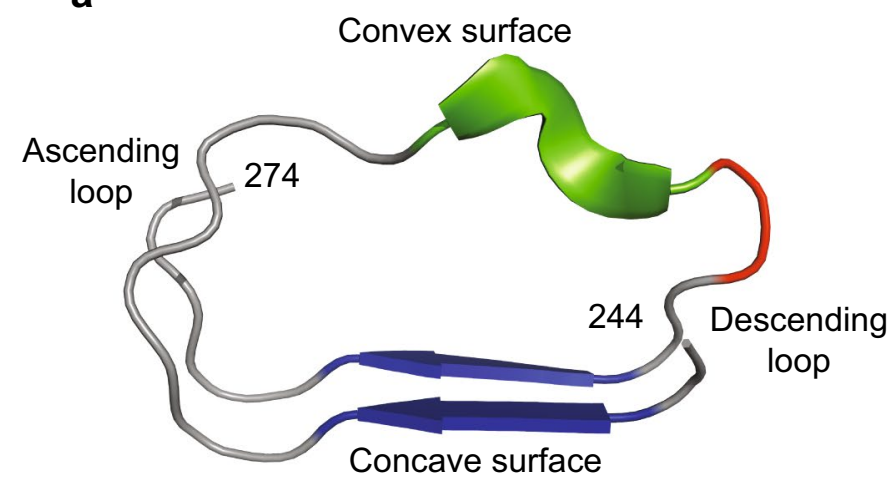

b

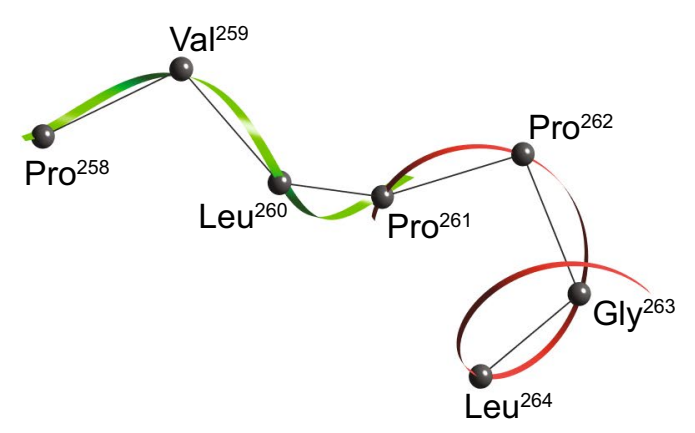

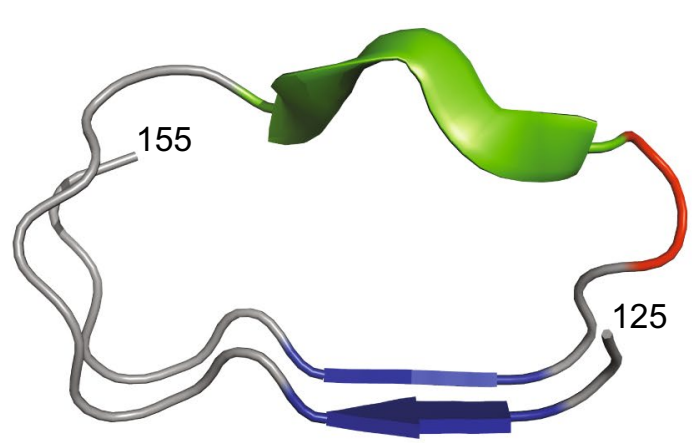

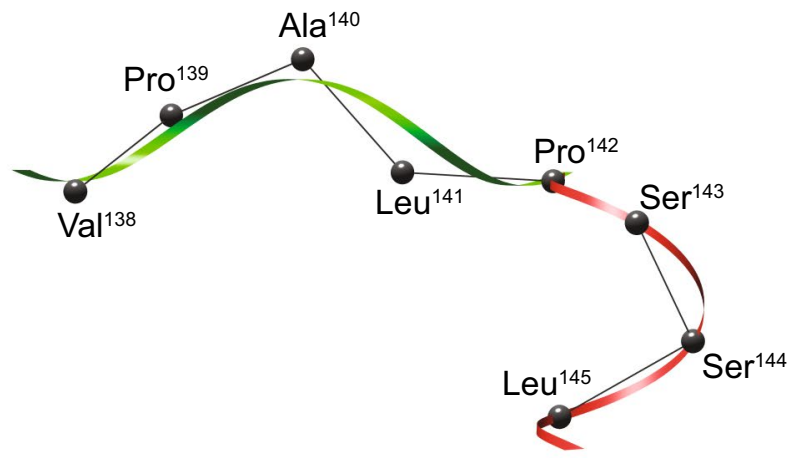

Fig. 3 Super secondary structure consisting of a PPII and a $\beta$-turn in bacterial LRRs. a Secondary structures. Left panel. Sequence 244-LRTLEVSGNQLTSLPVLPPGLLELSIFSNPL-274 in SspH2 (LRR3 and HCV of LRR4) (PDB ID: 3G06_A). Right panel. 125-LEELNLSYNGITTVPALPSSLVSLILSRTNI-155 in bovine TLR9 (LRR4 and HCS of LRR5) (PDB ID:3WPC_A). Blue arrows represent $\beta$-strands, green ribbons PPIIs, and red tubes $\beta$-turns. b Super secondary structure (HELFIT). Left panel. Sequence 258-PVLPPGL-264 in SspH2 (PDB ID: 3G06_A). The sequence PVLP is a part of the LRR3 VS which correspond to the underlined residues of xxLPxLPxx (the consensus of the N-type VS. The

indicates that these type I $\beta$-turns form a regular, right handed helix.

The helix parameters of LRR domains were determined for IpaH9.8 $(n=8), \mathrm{SspH} 1,(n=10), \mathrm{SspH} 2(n=13), Y$. pestis YopM $(n=16)$, Y. enterocolitica YopM $(n=21)$, and $\operatorname{SlrP}(n=12)$. The bacterial LRR domains are represented by a right handed helix (Table 5). The helix parameters range over: $P=47.3 \rightarrow 115 \AA, N=28.4 \rightarrow 41.3$ units/turn, $R=18.9 \rightarrow 24.6 \AA, \Delta z=1.67 \rightarrow 3.46 \AA$, and $\Delta \Phi=8.7^{\circ} \rightarrow$ $12.7^{\circ} ; p=0.03 \rightarrow 0.19 \AA$.

Figure 4 shows a plot of $2 \cdot R \cdot \sin (\Delta \Phi / 2)$ versus $\Delta z$. The values fall on a circle with radius $D$ (circle plot) [7]. $D$ is a function of $\Delta z, \Delta \Phi$, and $R$ [7].

$D=\left[\left\{2 R \sin \left(\frac{\Delta \Phi}{2}\right)\right\}^{2}+(\Delta z)^{2}\right]^{1 / 2}$ sequence PVLP adopt PPII and the PPGL adopt type I $\beta$-turn. The sequence PVLP is a part of the LRR3 VS which correspond to the underlined residues of xxLPxLPxx (the consensus of the N-type VS). The sequence PVLP adopts four residue PPII and the PPGL adopts type I $\beta$-turn. Right panel. Sequence 138-VPALPSSL-145 in bovine TLR9 (PDB ID: 3WPC_A). The sequence VPALP is a part of the LRR4 VS which correspond to the underlined residues of xxLPxLPxx. The sequence VPALP forms five residue PPII and the sequence PPSL forms one type I $\beta$-turn. Best fitted lines by HELFIT are colored green for PPIIs and red for $\beta$-turns, and $\alpha$-carbons grey. (Color figure online)

$D$ is the average $\mathrm{C}_{\alpha}(i)-\mathrm{C}_{\alpha}(i+1)$ distance between adjacent repeats- $i$ and $i+1 ; D$ corresponds to the interstrand distance. Equation 5 gives $D=4.97 \pm 0.10 \AA$; this allows the formation of hydrogen bonds between parallel strands. This circle plot shows that the helix pitch, $P$, and rise per turn, $\Delta z$, of bacterial LRR is comparable to those of SDS22-like and Plant specific LRRs; while it is larger than those of RI-like and CC LRRs [7].

\subsection{Geometrical Analysis}

Figure 5 shows the frequency distributions of three angles of $\Omega_{1}, \Omega_{2}$, and $\Omega_{3}$. The $\Omega_{1}$ angle shows an asymmetrical distribution (Fig. 5b). The $\Omega_{1}$ angle ranges from $70^{\circ}$ to $120^{\circ}$; the average value is $\sim 103^{\circ}$ (Table 4). The $\Omega_{2}$ and $\Omega_{3}$ have the average values of $\sim 33^{\circ}$ and $\sim 99^{\circ}$, respectively. 
Table 3 Helix parameters of PPIIs in bacterial LRRs

\begin{tabular}{lllllllll}
\hline & Programs & Number of PPII & $P(\AA)^{\mathrm{a}}$ & $N^{\mathrm{a}}$ & $R(\AA)^{\mathrm{a}}$ & $\Delta z(\AA)^{\mathrm{a}}$ & $p(\AA)$ & $V_{\mathrm{c}}\left(\AA^{3}\right)^{\mathrm{a}}$ \\
\hline PPII $^{\mathrm{b}}$ & - & - & 8.96 & 2.99 & 1.36 & 3.00 & - & 17.41 \\
PPII $^{\mathrm{c}}$ & - & - & 8.69 & 2.90 & 1.33 & 3.00 & - & 16.70 \\
PPII $^{\mathrm{d}}$ & - & - & 8.58 & 2.99 & 1.45 & 2.87 & - & 18.95 \\
PPII $^{\mathrm{e}}$ & - & - & 8.62 & 3.08 & 1.52 & 2.80 & - & 20.30 \\
Four residue PPII & DSSP-PPII & 50 & $8.61(0.40)$ & $2.82(0.13)$ & $1.25(0.05)$ & $3.06(0.05)$ & $0.10(0.03)$ & $15.07(1.07)$ \\
& PROSS & 67 & $8.52(0.51)$ & $2.78(0.21)$ & $1.23(0.09)$ & $3.07(0.08)$ & $0.10(0.04)$ & $14.70(1.74)$ \\
& SEGNO & 21 & $8.78(0.31)$ & $3.05(0.10)$ & $1.47(0.05)$ & $2.87(0.05)$ & $0.05(0.04)$ & $19.49(0.05)$ \\
& XLTSSTR & 130 & $8.45(0.38)$ & $2.75(0.15)$ & $1.23(0.07)$ & $3.07(0.07)$ & $0.10(0.04)$ & $14.49(1.49)$ \\
Five residue PPII & DSSP-PPII & 49 & $9.83(0.50)$ & $3.54(0.25)$ & $1.53(0.11)$ & $2.78(0.10)$ & $0.26(0.04)$ & $20.50(2.39)$ \\
& PROSS & 32 & $9.94(0.43)$ & $3.64(0.16)$ & $1.58(0.06)$ & $2.73(0.05)$ & $0.27(0.03)$ & $21.46(1.39)$ \\
& SEGNO & 132 & $10.05(0.37)$ & $3.65(0.15)$ & $1.57(0.07)$ & $2.75(0.07)$ & $0.27(0.04)$ & $21.38(1.62)$ \\
Six residue PPII & XLTSSTR & 43 & $10.17(1.22)$ & $3.54(0.39)$ & $1.47(0.16)$ & $2.88(0.18)$ & $0.29(0.09)$ & $19.39(3.10)$ \\
& SEGNO & 21 & $10.45(1.21)$ & $3.82(0.50)$ & $1.50(0.09)$ & $2.74(0.07)$ & $0.30(0.04)$ & $19.56(2.18)$ \\
& XLTSSTR & 14 & $13.91(1.64)$ & $6.10(0.71)$ & $2.40(0.09)$ & $2.28(0.05)$ & $0.45(0.04)$ & $41.36(2.92)$ \\
\hline
\end{tabular}

The number in the parentheses indicates standard deviations

${ }^{a} P$ helix pitch, $N$ residue number per turn, $R$ helix radius, $\Delta z$ helix rise per turn; $\operatorname{Vc}=\pi \mathrm{R}^{2}(\Delta z)$

${ }^{\mathrm{b}}(\Phi, \Psi)=(-75,150)$ by Jha [67]

${ }^{\mathrm{c}}(\Phi, \Psi)=(-75,145)$ by Hopfinger [25]

${ }^{\mathrm{d}}(\Phi, \Psi)=(-65,140)$ by Adzhubei [68]

${ }^{\mathrm{e}}(\Phi, \Psi)=(-60,140)$ by Schulz and Schirmer [26]

\section{Discussion}

\subsection{Structural Role of PPIIs in Bacterial LRRs}

The backbone dihedral angles $(\Phi, \Psi)$ of ideal PPII is $\left(-75^{\circ}\right.$, $\left.145^{\circ}\right)$ [23]. Other dihedral angles has been also proposed; $(\Phi, \Psi)=\left(-75^{\circ}, 140^{\circ}\right),\left(-65^{\circ}, 145^{\circ}\right)$, and $\left(-60^{\circ}, 140^{\circ}\right)$ (Table 3) $[26,67,68]$. It appears that four residue PPIIs in proteins are a near ideal form with $(\Phi, \Psi)=\left(-75^{\circ}, 145^{\circ}\right)$ or $\left(-75^{\circ}, 140^{\circ}\right)$.

The secondary structure assignment and the HELFIT analysis indicate that the N-subtype VS adopts one stretch of PPII of four, five, or six residues. In contrast, the T-subtype prefers two separate PPIIs consisting two or three and of two residues. Consequently, there is a clear difference in the PPII patterns between the two subtypes. The two hydrophobic residues in the VS part of the two subtypes are concentrated on the side that is oriented toward the hydrophobic core as well as other conserved hydrophobic residues in the HCS part (Fig. 6). This structural restriction makes the difference. The assignments by the four programs show different PPII patterns in most cases. This observation mainly comes from high flexibility of PPII due to no intrachain hydrogen bond.

The variable N-type VSs are seen in YopMRSLCDLPPS and SGLSELPPN (Supplementary Table S2). The first repeat of twelve LRRs in chondroadherin is also a variable N-subtype VS of QKIPKVSEK; the structure of human chondroadherin which forms tetramers in crystal has been determined at $2.1 \AA$ resolution [69]. Their secondary structure assignment sometimes shows no PPII or only short PPII of two or three residues. These observations indicate that two conserved prolines in the N-subtype VS parts are strongly required for the super secondary structure consisting of PPII and $\beta$-turn.

It may be significant that $\mathrm{Src}$ tyrosine kinases $\mathrm{SH} 3$ domain binds to short proline rich sequence of $\mathrm{xPxP}$ that forms PPII [70]. This sequence is very similar to LPxLP in the $\mathrm{N}$-subtype.

\subsection{Super Secondary Structure}

The present analyses demonstrate that the $\mathrm{N}$-subtype adopts a super secondary structure consisting of a PPII and a $\beta$-turn. Ananthanarayanan et al. [71] first described this super secondary structure. Tandem repeats of the super secondary structure form a novel helical structure called the polyproline, $\beta$-turn helix [72]. This structure is observed in tandem repeats of the hepta-peptide, YSPSPSPS, in the $C$-terminal repeat domain (CTD) of the large subunit of RNA polymerase II (POL II) [73-75]. Many factors involved in RNA processing bind the CTD [76].

The VSs of RI-like and CC LRRs adopt an $\alpha$-helical conformation ( $\beta-\alpha$ structural units). Typical LRR VSs 


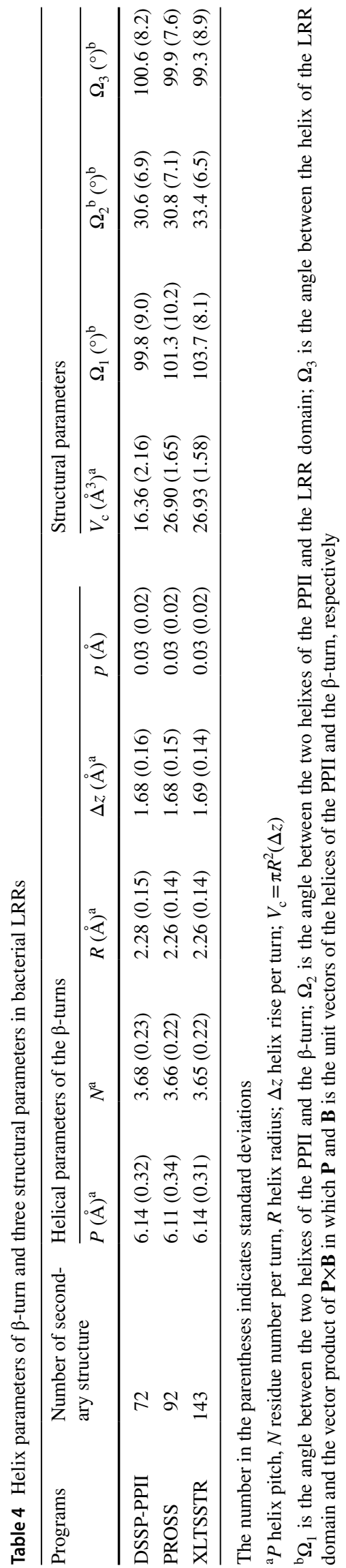

prefer tandem $\beta$-turns. The SDS22-like LRR VSs strongly prefer $3_{10}$-helix $\left(\beta-3_{10}\right)$. The Plant specific LRR structural unit is $\beta-\beta-3_{10}$. The occurrence of $\beta$-turns at the $C$-terminal sides of the VS parts are also observed in Plant specific, SDS22-like, and Typical LRRs as well as bacterial LRR [7]. Consequently, a super secondary structure consisting of $3_{10}$-helix and $\beta$-turns is present in Plant specific and SDS22-like LRRs. The unique super secondary structures consisting of $\beta$-turns and PPII, and of $\beta$-turns

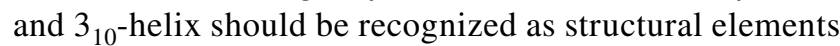
in proteins.

Here we propose a structural parameter that characterizes the super secondary structure; the parameter is the angle between the two helix axes of PPII and type I $\beta$-turn $\left(\Omega_{1}\right)$. Its average value is $\sim 103^{\circ}$. The $\Omega_{1}$ angle also helps to characterize other super secondary structures including those consisting of PPII and an $\alpha$-helix, and of PPII and a $3_{10}$-helix.

\subsection{Solenoid Structure of Bacterial LRR Domains}

The circle plot of bacterial LRR is comparable to those of SDS22-like and Plant specific LRR; while it differs from those of RI-like and CC LRRs (Fig. 4). We recently calculated helical parameters of 642 LRRs of known structures of 114 proteins by the HELFIT program [7]. The results indicate that the helical parameters are influenced by the structures of the ascending loops rather than of the descending loops, helical elements on the convex face, and the uniformity of parallel strand stacking on the concave face [1, 7]. The helix radius of PPII is the smallest between $\alpha$-helix, $3_{10}$-helix, $\pi$-helix, $\omega$-helix, and PPII. This partly contributes to a relatively large helix pitch for the bacterial LRR domains.

We determined the $\Omega_{2}$ angle between the helix axes of PPII and of the bacterial LRR domain. The VSs of SDS22like, Plant-specific, CC, and RI-like adopt $3_{10}$-helix or $\alpha$-helix instead of PPII. The comparison of the $\Omega_{2}$ angle with the angles between their helices and LRR domains may identify fundamental features of individual LRR classes.

\subsection{The PPII Assignment by the Four Programs}

In many methods for assignments of secondary structures from atomic coordinates, the termini of the segments are frequently ill-defined and it is difficult to decide unambiguously which residues at the edge of the segments have to be included [77]. In this study the PPII pattern assigned also differs between the four programs in most cases. The number of four, five, or six residue PPIIs assigned is larger in SEGNO and XLTSSTR than in DSSP-PPII and PROSS. However, the HELFIT analyses indicate that all PPIIs 
Table 5 Helix parameters of LRR domains in bacteria LRR proteins

\begin{tabular}{rllrllllll}
\hline & Protein & $n^{\mathrm{a}}$ & \multicolumn{1}{c}{$P(\AA)^{\mathrm{a}}$} & \multicolumn{1}{l}{$N^{\mathrm{a}}$} & $R(\AA)^{\mathrm{a}}$ & $\Delta z(\AA)^{\mathrm{a}}$ & $\Delta \Phi\left({ }^{\circ}\right)^{\mathrm{a}}$ & $p(\AA)^{\mathrm{a}}$ & PDB_chanis \\
\hline 1 & IpaH9.8 & 8 & 114.94 & 33.19 & 18.87 & 3.46 & 10.85 & 0.14 & 5B0N_A \\
& IpaH9.8 & 8 & 111.48 & 34.21 & 20.48 & 3.26 & 10.52 & 0.13 & 5B0N_B \\
3 & SspH2 & 13 & 76.72 & 30.57 & 21.57 & 2.51 & 11.78 & 0.03 & 3G06 \\
4 & YopM & 16 & 47.31 & 28.37 & 20.58 & 1.67 & 12.69 & 0.08 & 1JL5A \\
& YopM & 21 & 71.27 & 30.35 & 21.70 & 2.35 & 11.86 & 0.12 & 4OW2_A \\
& YopM & 21 & 67.16 & 30.46 & 22.10 & 2.20 & 11.82 & 0.14 & 4OW2_B \\
& YopM & 21 & 71.42 & 29.75 & 21.09 & 2.40 & 12.10 & 0.08 & 4OW2_C \\
5 & YopM & 21 & 70.50 & 29.58 & 20.99 & 2.38 & 12.17 & 0.09 & 4OW2_D \\
& SspH1 & 10 & 84.44 & 34.74 & 23.69 & 2.43 & 10.36 & 0.14 & 4NKH_A \\
& SspH1 & 10 & 88.78 & 35.95 & 24.31 & 2.47 & 10.01 & 0.13 & 4NKH_B \\
& SspH1 & 10 & 83.55 & 35.39 & 24.63 & 2.36 & 10.17 & 0.13 & 4NKH_C \\
& SspH1 & 10 & 89.67 & 34.39 & 23.14 & 2.61 & 10.47 & 0.16 & 4NKH_D \\
& SspH1 & 10 & 103.20 & 32.90 & 20.47 & 2.50 & 10.94 & 0.16 & 4NKH_E \\
& SspH1 & 10 & 83.66 & 41.32 & 29.48 & 2.02 & 8.71 & 0.19 & 4NKH_F \\
& SspH1 & 10 & 89.67 & 33.55 & 22.10 & 2.67 & 10.73 & 0.16 & 4NKG_A \\
& SspH1 & 10 & 87.89 & 30.75 & 19.83 & 2.86 & 11.71 & 0.15 & 4NKG_C \\
& IpaH3 & 9 & 89.22 & 35.25 & 24.13 & 2.53 & 10.21 & 0.07 & 3CVR \\
& slrP & 12 & 70.03 & 34.93 & 25.34 & 2.00 & 10.31 & 0.11 & 4PUF_A \\
& slrP & 12 & 54.07 & 35.31 & 26.44 & 1.53 & 10.20 & 0.15 & 4PUF_B \\
\hline
\end{tabular}

${ }^{a} n$ repeat number of LRRs, $P$ helix pitch, $N$ residue number per turn, $R$ helix radius, $\Delta z$ helix rise per turn, $\Delta \Phi$ rotation per repeat unit, $p$ helix regularity

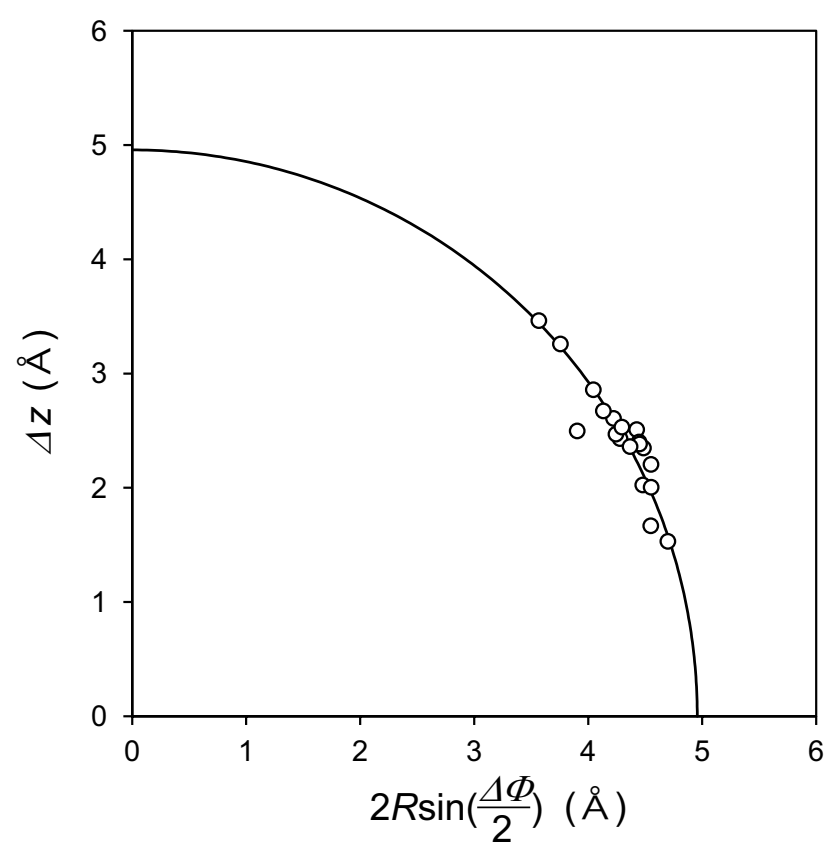

Fig. 4 The correlation of $\Delta \mathrm{z}$ and $2 \cdot R \cdot \sin (\Delta \Phi / 2)$ in the helix parameters of LRR domains in the seven bacterial LRR proteins assigned are unambiguously regular or irregular left handed polyproline helices with only a few exceptions. The combination of the secondary structure assignment programs (SEGNO and XLTSSTR) and the HELFIT analysis is useful for PPII assignment in proteins.

\section{Conclusions}

The present study shows that the $\mathrm{N}$-subtype bacterial LRRs are characterized by a unique super secondary structures consisting of PPII helices and a $\beta$-turn. In contrast, the T-subtype VS prefers two separate PPIIs with two or three or with only two residues. The type I $\beta$-turns can be regarded as regular, right handed helices. We propose three important structural parameters: the three angles between the two helix axes of PPII and $\beta$-turn, between two helix axes of PPII and LRR domain, and between the helix axis of LRR domain and the vector product of $\mathbf{P} \times \mathbf{B}$. These three angles characterize the super secondary structure and the LRR domain. 
a

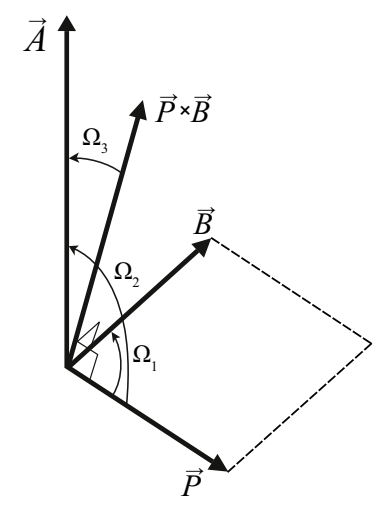

b
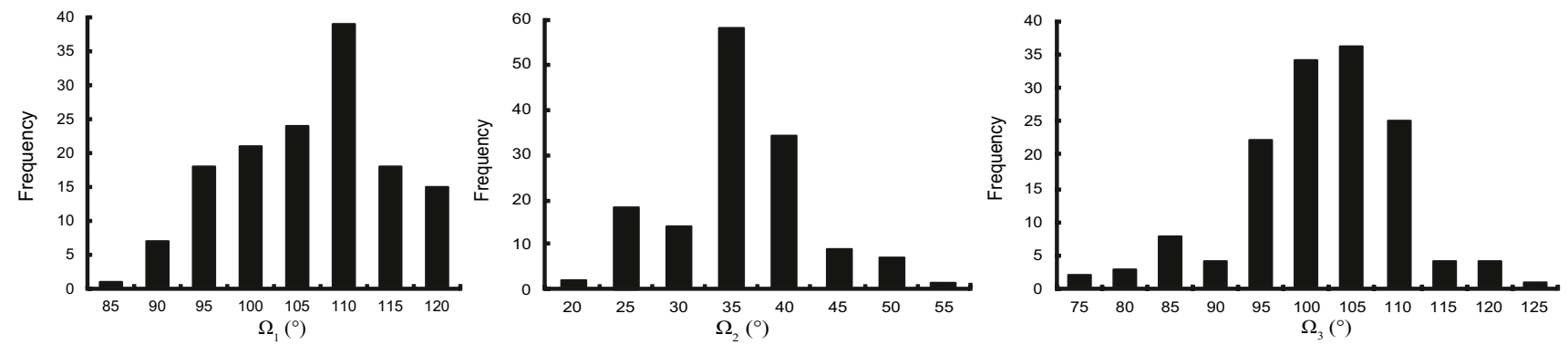

Fig. 5 Geometrical analysis of super secondary structure. a The definition of the three angles of $\Omega_{1}, \Omega_{2}$, and $\Omega_{3}$. b Frequency distributions of the $\Omega_{1}, \Omega_{2}$, and $\Omega_{3}$ angles (by the XLTSSTR program)

a

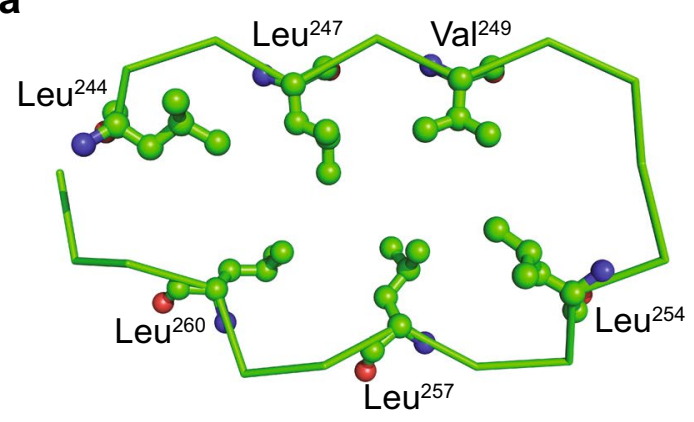

Fig. 6 Hydrophobic cores in the N-subtype (a) and T-subtype (b) of bacterial LRR. a Sequence 244-LRTLEVSGNQLTSLPVLPPG-263 (LRR3) in SspH2 (PDB ID: 3G06_A). b Sequence

Funding This study was funded by National University of Mongolia (FELLOWSHIP GRANT-P2016-1173) (to P. E.)

\section{Compliance with Ethical Standards}

Conflict of interest All authors declare that they have no conflicts of interest. b

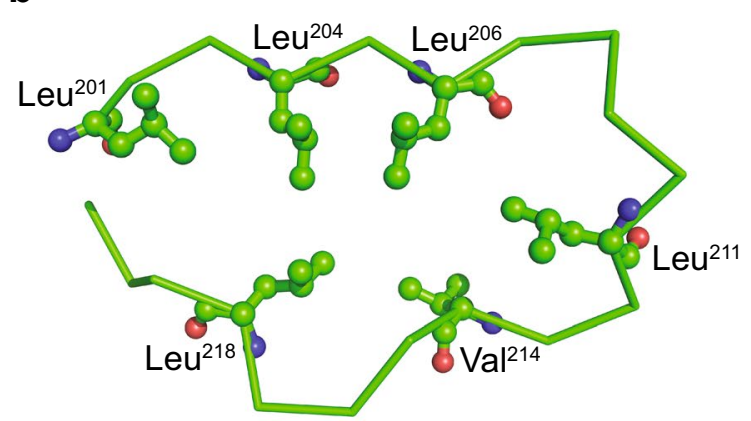

211-LTHLSLKYNNLTTVPRSLPPS-221 (LRR7) in bovine TLR9 (PDB ID:3WPC_A). Green is $\alpha$-carbon, red oxygen, and blue nitrogen. (Color figure online)

Open Access This article is distributed under the terms of the Creative Commons Attribution 4.0 International License (http://creativeco mmons.org/licenses/by/4.0/), which permits unrestricted use, distribution, and reproduction in any medium, provided you give appropriate credit to the original author(s) and the source, provide a link to the Creative Commons license, and indicate if changes were made. 


\section{References}

1. Matsushima N, Kretsinger RH (2016) Leucine rich repeats: sequences, structures, ligand-interactions, and evolution. LAMBERT Academic Publishing, Saarbrücken

2. Kobe B, Deisenhofer J (1994) The leucine-rich repeat: a versatile binding motif. Trends Biochem Sci 19:415-421

3. Kobe B, Kajava AV (2001) The leucine-rich repeat as a protein recognition motif. Curr Opin Struct Biol 1:725-732

4. Matsushima N, Tachi N, Kuroki Y, Enkhbayar P, Osaki M, Kamiya M, Kretsinger RH (2005) Structural analysis of leucinerich-repeat variants in proteins associated with human diseases. Cell Mol Life Sci 62:2771-2791

5. Bella J, Hindle KL, McEwan PA, Lovell SC (2008) The leucinerich repeat structure. Cell Mol Life Sci 65:2307-2333

6. Matsushima N, Enkhbayar P, Kamiya M, Osaki M, Kretsinger RH (2005) Leucine-rich repeats (LRRs): structure, function, evolution and interaction with ligands. Drug Design Rev 2:305-322

7. Enkhbayar P, Miyashita H, Kretsinger RH, Matsushima N (2014) Helical parameters and correlations of Tandem Leucine rich repeats in proteins. J Proteom Bioinform 7:139-150

8. Ng AC, Eisenberg JM, Heath RJ, Huett A, Robinson CM, Nau GJ, Xavier RJ (2011) Human leucine-rich repeat proteins: a genome-wide bioinformatic categorization and functional analysis in innate immunity. Proc Natl Acad Sci USA 108(Suppl 1):4631-4638

9. Tör M, Lotze MT, Holton N (2009) Receptor-mediated signalling in plants: molecular patterns and programmes. J Exp Bot 60:3645-3654

10. Coburn B, Sekirov I, Finlay BB (2007) Type III secretion systems and disease. Clin Microbiol Rev 20:535-549

11. Haraga A, Miller SI (2006) A Salmonella type III secretion effector interacts with the mammalian serine/threonine protein kinase PKN1. Cell Microbiol 8:837-846

12. Matsushima N, Ohyanagi T, Tanaka T, Kretsinger RH (2000) Super-motifs and evolution of tandem leucine-rich repeats within the small proteoglycans-biglycan, decorin, lumican, fibromodulin, PRELP, keratocan, osteoadherin, epiphycan, and osteoglycin. Proteins 38:210-225

13. Matsushima N, Kamiya M, Suzuki N, Tanaka T (2000) Supermotifs of leucine-rich repeats (LRRs) proteins. Genome Inform 11:343-345

14. Matsushima N, Tanaka T, Enkhbayar P, Mikami T, Taga M, Yamada K, Kuroki Y (2007) Comparative sequence analysis of leucine-rich repeats (LRRs) within vertebrate toll-like receptors. BMC Genom 8:24-143

15. Siligardi G, Drak AF (1995) The importance of extended conformations and, in particular, the PII conformation for the molecular recognition of peptides. Biopolymers 37:281-292

16. MacArthur MW, Thornton JM (1991) Influence of proline residues on protein conformation. J Mol Biol 218:397-412

17. Rath A, Davidson AR, Deber CM (2005) The structure of "unstructured" regions in peptides and proteins: role of the polyproline II helix in protein folding and recognition. Biopolymers 80:179-185

18. Vitagliano L, Berisio R, Mastrangelo A, Mazzarella L, Zagari A (2001) Preferred proline puckerings in cis and trans peptide groups: implications for collagen stability. Protein Sci 10:2627-2632

19. Adzhubei AA, Sternberg MJ (1993) Left-handed polyproline II helices commonly occur in globular proteins. J Mol Biol 229:472-493

20. Stapley BJ, Creamer TP (1993) A survey of left-handed polyproline II helices. Protein Sci 8:587-595
21. Cubellis MV, Caillez F, Blundell TL, Lovell SC (2005) Properties of polyproline II, a secondary structure element implicated in protein-protein interactions. Proteins 58:880-892

22. Berisio R, Loguercio S, De Simone A, Zagari A, Vitagliano L (2006) Polyproline helices in protein structures: a statistical survey. Protein Pept Lett 13:847-854

23. Barlow DJ, Thornton JM (1988) Helix geometry in proteins. J Mol Biol 201:601-619

24. Creamer TP, Campbell MN (2012) Determinants of the polyproline II helix from modeling studies. Adv Protein Chem 62:263-282

25. Hopfinger A (2012) Conformational properties of macromolecules. Elsevier, Amsterdam

26. Schulz GE, Schirmer RH (1979) Principles of protein structure. Springer, Berlin

27. Kumar P, Bansal M (2016) Structural and functional analyses of PolyProline-II helices in globular proteins. J Struct Biol 196:414-425

28. Kabsch W, Sander C (1983) Dictionary of protein secondary structure: pattern recognition of hydrogen-bonded and geometrical features. Biopolymers 22:2577-2637

29. Frishman D, Argos P (1995) Knowledge-based protein secondary structure assignment. Proteins 23:566-579

30. Berman HM, Kleywegt GJ, Nakamura H, Markley JL (2014) The protein data bank archive as an open data resource. J Comput Aided Mol Des 28:1009-1014

31. Mansiaux Y, Joseph AP, Gelly JC, de Brevern AG (2011) Assignment of PolyProline II conformation and analysis of sequence-structure relationship. PLoS ONE 6:e18401

32. Srinivasan R, Rose GD (1999) A physical basis for protein secondary structure. Proc Natl Acad Sci USA 96:14258-14263

33. Cubellis MV, Cailliez F, Lovell SC (2005) Secondary structure assignment that accurately reflects physical and evolutionary characteristics. BMC Bioinform 6(Suppl 4):S8

34. King SM, Johnson WC (1999) Assigning secondary structure from protein coordinate data. Proteins 35:313-320

35. Kumar P, Bansal M (2005) Identification of local variations within secondary structures of proteins. Acta Crystallogr 71:1077-1086

36. Richards FM, Kundrot CE (1988) Identification of structural motifs from protein coordinate data: secondary structure and firstlevel supersecondary structure. Proteins 3:71-84

37. Chiang YS, Gelfand TI, Kister AE, Gelfand IM (2007) New classification of supersecondary structures of sandwich-like proteins uncovers strict patterns of strand assemblage. Proteins 68:915-921

38. Adzhubei AA, Sternberg MJ (1994) Conservation of polyproline II helices in homologous proteins: implications for structure prediction by model building. Protein Sci 3:2395-2410

39. Evdokimov AG, Anderson DE, Routzahn KM, Waugh DS (2001) Unusual molecular architecture of the Yersinia pestis cytotoxin YopM: a leucine-rich repeat protein with the shortest repeating unit. J Mol Biol 312:807-821

40. Park H, Huxley-Jones J, Boot-Handford RP, Bishop PN, Attwood TK, Bella J (2008) LRRCE: a leucine-rich repeat cysteine capping motif unique to the chordate lineage. BMC Genom 9:599

41. Adzhubei AA, Sternberg MJ, Makarov AA (2013) Polyproline-II helix in proteins: structure and function. J Mol Biol 425:2100-2132

42. Keszei AF, Tang X, McCormick C, Zeqiraj E, Rohde JR, Tyers M, Sicheri F (2014) Structure of an SspH1-PKN1 complex reveals the basis for host substrate recognition and mechanism of activation for a bacterial E3 ubiquitin ligase. Mol Cell Biol 34:362-373

43. Quezada CM, Hicks SW, Galan JE, Stebbins CE (2009) A family of Salmonella virulence factors functions as a distinct class of autoregulated E3 ubiquitin ligases. Proc Natl Acad Sci USA 106:4864-4869 
44. Zhu Y, Li H, Hu L, Wang J, Zhou Y, Pang Z, Liu L, Shao F (2008) Structure of a Shigella effector reveals a new class of ubiquitin ligases. Nat Struct Mol Biol 15:1302-1308

45. Takagi K, Kim M, Sasakawa C, Mizushima T (2016) Crystal structure of the substrate-recognition domain of the Shigella E3 ligase IpaH9.8. Acta Crystallogr 72:269-275

46. Zouhir S, Bernal-Bayard J, Cordero-Alba M, Cardenal-Munoz E, Guimaraes B, Lazar N, Ramos-Morales F, Nessler S (2014) The structure of the Slrp-Trx1 complex sheds light on the autoinhibition a of the type III secretion system effectors of the NEL family. Biochem J 464:135-144

47. Kokatla HP, Sil D, Tanji H, Ohto U, Malladi SS, Fox LM, Shimizu T, David SA (2014) Structure-based design of novel human Tolllike receptor 8 agonists. ChemMedChem 9:719-723

48. Ohto U, Shibata T, Tanji H, Ishida H, Krayukhina E, Uchiyama S, Miyake K, Shimizu T (2015) Structural basis of CpG and inhibitory DNA recognition by Toll-like receptor 9. Nature 520:702-705

49. Tanji H, Ohto U, Shibata T, Miyake K, Shimizu T (2013) Structural reorganization of the toll-like receptor 8 dimer induced by agonistic ligands. Science 339:1426-1429

50. Paracuellos P, Kalamajski S, Bonna A, Bihan D, Farndale RW, Hohenester E (2017) Structural and functional analysis of two small leucine-rich repeat proteoglycans, fibromodulin and chondroadherin. Matrix Biol 63:106-116

51. Scott PG, McEwan PA, Dodd CM, Bergmann EM, Bishop PN, Bella J (2004) Crystal structure of the dimeric protein core of decorin, the archetypal small leucine-rich repeat proteoglycan. Proc Natl Acad Sci USA 101:15633-15638

52. Scott PG, Dodd CM, Bergmann EM, Sheehan JK, Bishop PN (2006) Crystal structure of the biglycan dimer and evidence that dimerization is essential for folding and stability of class I small leucine-rich repeat proteoglycans. J Biol Chem 281:13324-13332

53. Seiradake E, del Toro D, Nagel D, Cop F, Härtl R, Ruff T, SeyitBremer G, Harlos K, Border EC, Acker-Palmer A, Jones EY, Klein R (2014) FLRT structure: balancing repulsion and cell adhesion in cortical and vascular development. Neuron 84:370-385

54. Lu YC, Nazarko OV, Sando R 3rd, Salzman GS, Südhof TC, Araç D (2015) Structural basis of latrophilin-FLRT-UNC5 interaction in cell adhesion. Structure 23:1678-1691

55. Ranaivoson FM, Liu Q, Martini F, Bergami F, von Daake S, Li S, Lee D, Demeler B, Hendrickson WA, Comoletti D (2015) Structural and mechanistic insights into the latrophilin3-FLRT3 complex that mediates glutamatergic synapse development. Structure 23:1665-1677

56. Jackson VA, Mehmood S, Chavent M, Roversi P, Carrasquero M, Del Toro D, Seyit-Bremer G, Ranaivoson FM, Comoletti D, Sansom MS, Robinson CV, Klein R, Seiradake E (2016) Supercomplexes of adhesion GPCRs and neural guidance receptors. Nat Commun 17:11184

57. Enkhbayar P, Damdinsuren S, Osaki M, Matsushima N (2008) HELFIT: helix fitting by a total least squares method. Comput Biol Chem 32:307-310

58. Matsushima N, Miyashita H, Mikami T, Yamada K (2011) A new method for the identification of leucine-rich repeats by incorporating protein secondary structure prediction. Tuteja R (ed) Bioinformatics: genome bioinformatics and computational biology. NOVA Sience Pulishers, Hauppauge, pp 61-88

59. Chebrek R, Leonard S, de Brevern AG, Gelly JC (2014) PolyprOnline: polyproline helix II and secondary structure assignment database. Database 2014:bau102

60. Hutchinson EG, Thornton JM (1996) PROMOTIF-a program to identify and analyze structural motifs in proteins. Protein Sci $5: 212-220$
61. Heinig M, Frishman D (2004) STRIDE: a web server for secondary structure assignment from known atomic coordinates of proteins. Nucleic Acids Res 32(WebServer issue):W500-W5022

62. Pettersen EF, Goddard TD, Huang CC, Couch GS, Greenblatt DM, Meng EC, Ferrin TE (2004) UCSF Chimera-a visualization system for exploratory research and analysis. J Comput Chem 25:1605-1612

63. Enkhbayar P, Hikichi K, Osaki M, Kretsinger RH, Matsushima N (2006) 3(10)-helices in proteins are parahelices. Proteins 64:691-699

64. Enkhbayar P, Boldgiv B, Matsushima N (2010) Omega-Helices in proteins. Protein J 29:242-249

65. Matsushima N, Miyashita H, Enkhbayar P, Kretsinger RH (2015) Comparative geometrical analysis of leucine-rich repeat structures in the nod-like and toll-like receptors in vertebrate innate immunity. Biomolecules 5:1955-1978

66. Wilmot CM, Thornton JM (1988) Analysis and prediction of the different types of beta-turn in proteins. J Mol Biol 203:221-232

67. Jha AK, Colubri A, Zaman MH, Koide S, Sosnick TR, Freed KF (2005) Helix, sheet, and polyproline II frequencies and strong nearest neighbor effects in a restricted coil library. Biochemistry 44:9691-9702

68. Adzhubei AA, Eisenmenger F, Tumanyan VG, Zinke M, Brodzinski S, Esipova NG (1987) Approaching a complete classification of protein secondary structure. J Biomol Struct Dyn 5:689-704

69. Rämisch S, Pramhed A, Tillgren V, Aspberg A, Logan DT (2017) Crystal structure of human chondroadherin: solving a difficult molecular-replacement problem using de novo models. Acta Crystallogr 73:53-63

70. Kay BK, Williamson MP, Sudol M (2000) The importance of being proline: the interaction of proline-rich motifs in signaling proteins with their cognate domains. FASEB J 14:231-241

71. Ananthanarayanan VS, Soman KV, Ramakrishnan C (1987) A novel supersecondary structure in globular proteins comprising the collagen-like helix and beta-turn. J Mol Biol 198:705-709

72. Matsushima N, Creutz CE, Kretsinger RH (1990) Polyproline, beta-turn helices. Novel secondary structures proposed for the tandem repeats within rhodopsin, synaptophysin, synexin, gliadin, RNA polymerase II, hordein, and gluten. Proteins 7:125-155

73. Meredith GD, Chang WH, Li Y, Bushnell DA, Darst SA, Kornberg RD (1996) The C-terminal domain revealed in the structure of RNA polymerase II. J Mol Biol 258:413-419

74. Kumaki Y, Matsushima N, Yoshida H, Nitta K, Hikichi K (2001) Structure of the YSPTSPS repeat containing two SPXX motifs in the CTD of RNA polymerase II: NMR studies of cyclic model peptides reveal that the SPTS turn is more stable than SPSY in water. Biochim Biophys Acta 1548:81-93

75. Cramer P, Bushnell DA, Kornberg RD (2001) Structural basis of transcription: RNA polymerase II at 2.8 angstrom resolution. Science 292:1863-1876

76. Hsin JP, Manley JL (2012) The RNA polymerase II CTD coordinates transcription and RNA processing. Genes Dev 26:2119-2137

77. Martin J, Letellier G, Marin A, Taly JF, de Brevern AG, Gibrat JF (2005) Protein secondary structure assignment revisited: a detailed analysis of different assignment methods. BMC Struct Biol 5:17

78. Crooks GE, Hon G, Chandonia JM, Brenner SE (2004) WebLogo: a sequence logo generator. Genome Res 14:1188-1190 